\title{
Ultrastructural observations on rabbit blastocysts after maternal exposure to cadmium chloride
}

\author{
R. Abraham, N. Ringwood and R. Mankes \\ Institute of Experimental Pathology and Toxicology, Albany Medical College, Albany, \\ New York 12208, U.S.A.
}

\begin{abstract}
Summary. Cadmium chloride $\left(\mathrm{CdCl}_{2}\right)(0 \cdot 1$ or $1 \cdot 0 \%)$ was given in the drinking water to pregnant rabbits on Days 0 to 5 of gestation. Electron microscopy of the blastocysts revealed significant changes in the lysosomes (e.g. autophagic vacuoles and residual bodies) of endodermal cells as well as those of the inner cell mass. No such changes were evident in the trophoblast.
\end{abstract}

\section{Introduction}

The effects of environmental chemicals on the preimplantation embryo have been little studied. The viability of the preimplantation embryo and the degree of damage it sustains may determine the expression of the preimplantation embryo later in gestational development. Major genotoxic effects are usually manifest by death of the embryo before implantation, while minor damage may result in developmental abnormalities, spontaneous abortions or malformations. Certain chemicals have been shown to produce adverse responses of the blastocyst. For example, cyclosiloxanes, used in cosmetics, toiletries and breast implants, are selectively taken by and stored in rabbit blastocyst lysosomes (Abraham, Fulfs, Golberg \& Coulston, 1973). Similarly, copper used as an IUD caused cell death in rabbit and rat blastocysts following its interaction with lysosomal membranes and release of their contained enzymes (Abraham, Mankes, Fulfs, Golberg \& Coulston, 1974; Mankes, Estel, Abraham \& Skalko, 1976). In the present experiment, the effects of $\mathrm{CdCl}_{2}$ on rabbit blastocysts are reported.

\section{Materials and Methods}

New Zealand White rabbits ranging in weight from 3.4 to $5.8 \mathrm{~kg}$ were used. The 6 females were fed Wayne Diet (Toledo, Ohio) ad libitum, maintained under controlled lighting conditions of $12 \mathrm{~h}$ light $/ 24 \mathrm{~h}$ and acclimatized to laboratory conditions for at least 1 week before mating. The animals were mated and the presence of spermatozoa in a vaginal smear was designated to Day 0 of gestation. Groups of animals were treated through the drinking water with 0.1 or $1 \%$ cadmium chloride in distilled water or distilled water alone on Days 0 to 5 of gestation.

Between Days 5 and 6 of gestation the rabbits were anaesthetized with pentobarbitone sodium given via the marginal ear vein. The abdomen was then opened and the uterus removed and washed in saline solution $(9 \mathrm{~g} \mathrm{NaCl} / 1)$. A longitudinal incision was made in the uterine wall and the blastocysts were carefully removed with a metal spatula. From the 2 control rabbits, 8 blastocysts ( 4 from each) were obtained and all were examined. Five blastocysts were obtained from the $0 \cdot 1 \%$ 
$\mathrm{CdCl}_{2}$-treated rabbits $(\mathrm{N}=2)$ and 9 from the $1 \% \mathrm{CdCl}_{2}$-treated rabbits $(\mathrm{N}=2): 5$ blastocysts from each group were examined. The blastocysts were then transferred to vials and fixed in $2.5 \%$ glutaraldehyde in Sorenson's phosphate buffer and post-fixed in $\mathrm{OsO}_{4}$ in phosphate buffer. The tissue was then dehydrated in a graded series of alcohols, embedded in Epon 812 and sectioned. Sections $0.5 \mu \mathrm{m}$ thick were stained with $1 \%$ toludine blue and examined in a light microscope for orientation and general histopathological changes. A minimum of 5 (and up to 20) separate areas were selected per blastocyst and thin sections $(600-900 \mathrm{~nm})$ were cut and examined by electron microscopy. Sections $600 \mathrm{~nm}$ thick were examined in an RCA EMU-4 electron microscope.

\section{Results}

The fine structure of the rabbit blastocyst has been fully described by Enders (1971). Plate 1, Fig. 1 illustrates the typical features associated with the blastocyst and is representative of controls. The most pronounced cellular alteration evident after exposure of does to $\mathrm{CdCl}_{2}$ (both dose levels) was the change in the lysosomal system of the blastocysts. The observed changes in the lysosomes appeared to be related to the level of cadmium chloride exposure. Blastocysts obtained from rabbits receiving $0.1 \% \mathrm{CdCl}_{2}$ showed formation of secondary lysosomes in the cytoplasm of the endodermal cells in the form of autophagic vacuoles with recognizable cellular constituents such as mitochondria and free ribosomes (Pl. 1, Fig. 2). At the higher concentration of $\mathrm{CdCl}_{2}(1.0 \%)$, the endoderm and inner cell mass cells contained secondary lysosomes (Pl. 2, Figs 3 \& 4). These lysosomes displayed a variety of inclusions ranging from recognizable cellular organelles to partly or wholly digested membrane fragments (Pl. 1, Fig. 2; Pl. 2, Figs 3 \& 4). No such effects were noted in cells of the trophoblast.

\section{Discussion}

Most inorganic cations such as iron, lead, nickel, gold, cadmium, mercury and beryllium are taken up by and accumulate in the lysosomal system of various tissues (see review by Davies \& Allison, 1972). The acid glycolipid component of the lysosomal matrix exhibits a high affinity for cationic molecules, thus favouring their accumulation within lysosomes. Mixed copolymers of phenylmethylcyclosiloxane and copper are taken up by rabbit blastocyst lysosomes, with the ensuing cytotoxicity of the released lysosomal enzymes (Abraham et al., 1973, 1974). The present experiments demonstrate that $\mathrm{CdCl}_{2}$ induces lysosomal alterations similar to those observed with copper (Abraham et al., 1974). The presence of lysosomal alterations, indicative of cell damage (Davies \& Allison, 1972) in the inner cell mass and endodermal cells, but not in the trophoblast, suggests that post-implantation effects of $\mathrm{CdCl}_{2}$, such as resorptions and teratogenicity, may be due to the damaged cells of the inner cell mass. These interpretations are reinforced by investigations in progress wherein $\mathrm{CdCl}_{2}$ selectively inhibits DNA synthesis in the cells of the inner cell mass.

This work was supported in part by a NIEHS Training Grant 5T32-ES-07058 04-05 and a basic research grant kindly provided by the Shell Internationale Research Maatschappij B.V.

We thank Ms. Francine Marcoux for help with the preparation of the manuscript.

\section{PLATE 1}

Fig. 1. Electron micrograph of a portion of a normal 6-day rabbit blastocyst, showing the trophoblast $(\mathrm{t})$ and the inner cell mass (icm). $\times 12000$.

Fig. 2. Blastocyst from a rabbit given $0 \cdot 1 \% \mathrm{CdCl}_{2}$. Note the lysosomal residual body (av) in the endodermal cell (e). icm $=$ inner cell mass, $t=$ trophoblast. $\times 12000$. 


\section{PLATE I}
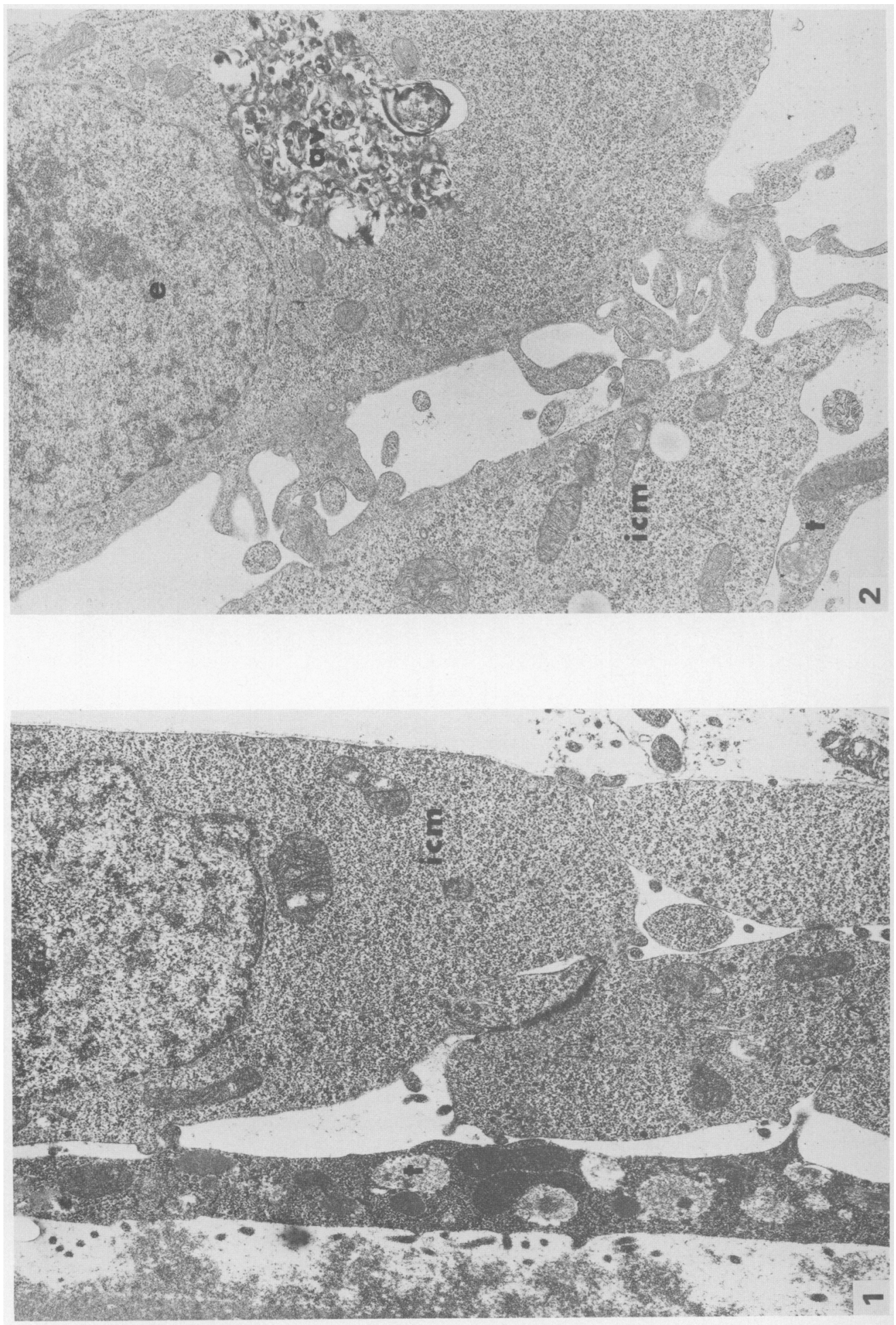

(Facing p. 324) 
PLATE 2

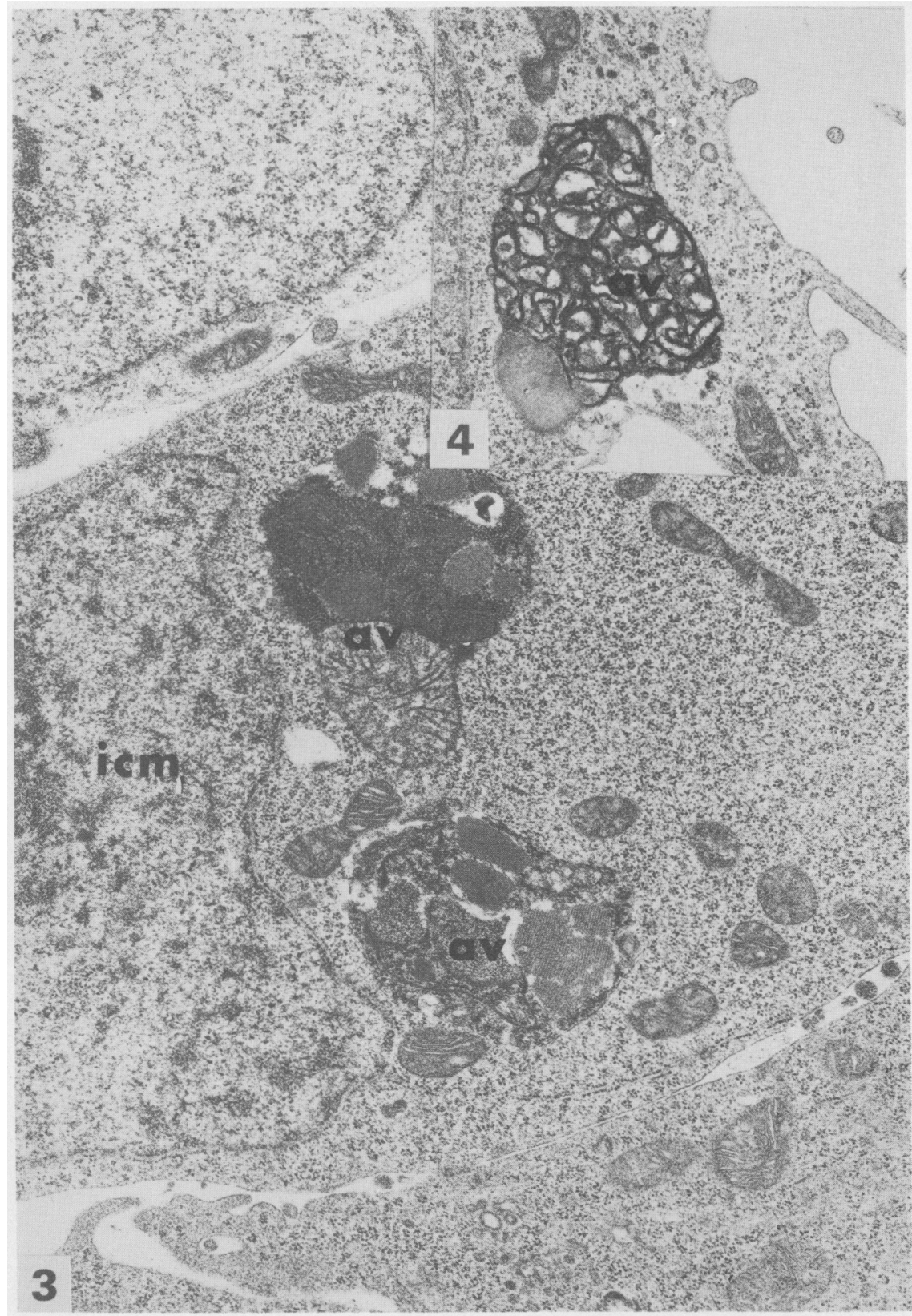

Fig. 3. The inner cell mass (icm) is illustrated in this electron micrograph of a blastocyst from a rabbit receiving $1.0 \% \mathrm{CdCl}_{2}$. The two autophagic vacuoles (av) in the inner cell mass have sequestered recognizable cellular constituents. $\times 14600$.

Fig. 4. A residual body, demonstrating the digestion of cellular elements in an endodermal cell. $\times 14600$. 


\section{References}

Abraham, R., Fulfs, J., Golberg, L. \& Coulston, F. (1973) Cytotoxic action of a mixed copolymer of phenylmethylcyclosiloxane on rabbit blastocyst lysosomes. J. Reprod. Fert. 34, 451-456.

Abraham, R., Mankes, R., Fulfs, J., Golberg, L. \& Coulston, F. (1974) Effects of intrauterine copper wire on blastocyst and uterine lysosomes of the rabbit: a cytochemical and ultrastructural study. $J$. Reprod. Fert. 36, 59-67.
Davies, P. \& Allison, A.C. (1972) The significance of the lysosome in toxicology. Crit. Rev. Toxicol. 1, 283-323.

Enders, A.C. (1971) The fine structure of the blastocyst. In The Biology of the Blastocyst, pp. 71-94. Ed. R. J. Blandau. University of Chicago Press.

Mankes, R., Estel, G., Abraham, R. \& Skalko, R. (1976) Reproductive effects of intrauterine devices in the rat. Toxicol. appl. Pharmacol. 37, 125.

Received 27 June 1983 